Revista Brasileira de Informática na Educação - RBIE

Brazilian Journal of Computers in Education

(ISSN online: 2317-6121; print: 1414-5685)

http://br-ie.org/pub/index.php/rbie

Submission: 22/Jan/2016; Camera ready: 27/May/2017;
New version: 25/Feb/2017; Available online: 21/Oct/2017; $2^{\text {nd }}$ round notif.: 26/May/2017;

Published: 30/Oct/2017

\title{
Uma abordagem baseada no ambiente Robocode para ensino de programação no Ensino Médio
}

\section{Title: An approach based on Robocode environment for teaching programming in high school}

Eliana Pantaleão

FACOM/UFU - Patos de Minas

epantaleao@ufu.br

\author{
Laurence Rodrigues do Amaral \\ FACOM/UFU - Patos de Minas \\ laurence@ufu.br
}

\author{
Gláucia Braga e Silva \\ IEF/UFV - Florestal \\ glaucia@ufv.br
}

\begin{abstract}
Resumo
Esse artigo descreve uma metodologia para o uso da ferramenta Robocode no ensino de algoritmos e programação de computadores para alunos do Ensino Médio. A metodologia inclui a participação de alunos de graduação que já cursaram as disciplinas de programação de computadores e que atuam como tutores e co-orientadores dos alunos. $O$ ambiente Robocode foi utilizado como ferramenta de apoio ao ensino de Java. Os resultados observados apontam o interesse dos alunos do Ensino Médio pela programação e também o potencial do Robocode como ferramenta lúdica de apoio ao ensino de Java. Por fim, com a realização dos Torneios de Robocode, foi possível observar o quanto a competitividade influenciou a motivação dos estudantes em aprender e superar desafios.
\end{abstract}

Palavras-chave: Robocode; ensino de Java; linguagem de programação; jogo educativo

\section{Resumo}

This paper describes a methodology for teaching algorithms and programming languages teaching in high school with the aid of the Robocode platform. The experience was developed since 2012 with the help of undergraduate students that had already concluded courses on computer programming and acted as tutors and co-advisors of the younger students. Robocode environment was used as a support tool, using a playful learning strategy, providing an early contact of the high-school students with Java programming language. The obtained results show the interest of high school students to learn computer programming. Furthermore, the Robocode platform proved to be a playful tool to support the teaching of Java. Finally, with the realization of the Robocode Tournaments, it was possible to observe how the competitiveness influenced the motivation of students to learn and overcome challenges.

Palavras-chave: Robocode; Java learning; programming language; educational game

Cite as: Pantaleão, E.,...\& Amaral, L. R., ..\&\& Braga e Silva, G. (2017) An approach based on Robocode environment for teaching programming in high school (Uma abordagem baseada no ambiente Robocode para ensino de programação no Ensino Médio). Brazilian Journal of Computers in Education (Revista Brasileira de Informática na Educação - RBIE), 25(3), 95-111. DOI: 10.5753/RBIE.2017.25.3.95 . 


\section{Introdução}

Nos últimos anos, observam-se o esforço e o interesse na pesquisa e no desenvolvimento de recursos tecnológicos voltados a apoiar o processo de ensino-aprendizagem. Em especial, destacam-se ferramentas computacionais que oferecem ambientes lúdicos e interativos, capazes de atrair a atenção de crianças e jovens, aumentando o interesse e favorecendo a aprendizagem de conteúdos escolares.

Na busca pela inovação, criatividade e motivação nas práticas pedagógicas, jogos digitais têm sido considerados um importante recurso tecnológico de apoio à educação, uma vez que aumenta o engajamento e a motivação do aprendiz. A diversão inerente ao ambiente lúdico e encantador de um jogo amplia as possibilidades de interesse e absorção do conteúdo educacional a ser trabalhado.

Diversos trabalhos endereçam o uso de jogos no ensino de programação e de pensamento computacional, não só para alunos de cursos na área tecnológica, mas também no âmbito da educação básica (T. R. Silva, Medeiros, \& Aranha, 2014)(Raabe, Zanchett, \& Vahldick, 2015)(Oliveira, Bettio, Rodarte, Braz, \& Ferrari, 2014)(Rodrigues, Andrade, Guerrero, \& Sampaio, 2015)(Reis et al., 2014)(Zanetti \& Oliveira, 2015). T. R. Silva et al. (2014) destacam que aprender programar é uma tarefa difícil e complexa aos olhos dos iniciantes e que uma abordagem com uso de jogos poderia, então, facilitar esse aprendizado.

O ensino de algoritmos e linguagens de programação busca nas Ciências Exatas seu pilar de sustentação, pois disciplinas nessa área despertam o raciocínio lógico-matemático para resolução de problemas (Santos \& Costa, 2006). Por esse motivo, estuda-se hoje a inclusão do ensino de programação de computadores o mais cedo possível, ou seja, no Ensino Médio e até mesmo no Ensino Fundamental. Nos EUA, a Association for Computing Machinery (ACM), juntamente com outras instituições, propõe iniciativas de levar Computação ao Ensino Médio: a iniciativa CS10K objetiva levar 10 mil professores de Computação ao Ensino Médio distribuídos em 10 mil escolas (Astrachan \& Briggs, 2012). Uma outra iniciativa relacionada é a APCS Principles que pretende validar créditos do Ensino Médio no Ensino Superior. O primeiro curso seguindo a formatação estabelecida será oferecido em 2016 (AP Computer Science Principles, n.d.). No Brasil, merece destaque o Scalable Game Design Brasil (SGD-Br) (PUC-Rio/SERG, n.d.-b), um projeto de pesquisa associado ao Scalable Game Design da Universidade do Colorado. O SGD$\mathrm{Br}$ buscou desenvolver tec-nologias para o ensino-aprendizado de raciocínio computacional para alunos do Ensino Fundamental do Estado do Rio de Janeiro, tal como a ferramenta PoliFacets (PUC-Rio/SERG, n.d.-a). A pesquisa brasileira é realizada pelo Grupo de Pesquisa em Engenharia Semiótica (SERG) da PUC-Rio e pelo Laboratório de Documentação Ativa e Design Inteligente (ADDLabs) da Universidade Federal Fluminense, com o apoio da AgentSheets, Inc. A nível mundial, a iniciativa Code.org (Code.org, n.d.) atua através de um site na internet com conteúdos disponíveis em 46 idiomas, incluindo o português do Brasil. Com o lema "Todos podem aprender", Code.org é uma organização sem fins lucrativos que defende o princípio de que computação é um conhecimento tão fundamental quanto química, matemática, biologia ou história. De acordo com seu fundador, Hadi Partovi, essas matérias ajudam o estudante a entender como funciona o mundo à nossa volta. Como atualmente a tecnologia é parte integrante desse mundo, conceitos básicos como algoritmos, protocolos de comunicação e linguagens de programação deveriam ser 
incluídos no ensino básico.

Diante do exposto, o problema abordado neste trabalho consiste em investigar uma nova abordagem para inserção de programação no Ensino Médio como forma de despertar e/ou fortalecer o raciocínio lógico-matemático dos estudantes. Para isso, acredita-se no potencial de motivação dos jogos, enquanto ferramentas de apoio à aprendizagem, aliado a uma estratégia de integração entre universidade e escola.

Assim, este trabalho apresenta uma abordagem para ensino de programação no Ensino Médio, baseada no uso do ambiente Robocode como ferramenta de apoio ao ensino da linguagem de programação Java, visando apresentar conceitos básicos da programação para os estudantes de forma rápida e divertida. Como objetivos específicos, destacam-se: a) despertar nos estudantes o interesse pela programação; b) trabalhar o raciocínio lógico-matemático dos estudantes, principal pilar das Ciências Exatas; c) avaliar o uso do Robocode enquanto ferramenta de apoio ao processo de ensino e de aprendizagem da programação; d) realizar competições como forma de estimular o aprendizado; e e) aproximar universidade e escola pública.

Essa abordagem tem sido aplicada na Universidade Federal de Uberlândia - campus Patos de Minas, nos anos de 2012 a 2015, no âmbito do ensino, da pesquisa e da extensão universitária, junto às escolas públicas da cidade de Patos de Minas, MG.

O embasamento teórico, o detalhamento da abordagem proposta e os resultados obtidos encontram-se descritos nas próximas seções. Na seção 2, discutem-se os trabalhos relacionados. A seção 3 apresenta o embasamento teórico acerca do uso de jogos como tecnologias de apoio à educação. Na seção 4, é apresentada uma visão geral da Plataforma Robocode. A seção 5, por sua vez, detalha a abordagem de ensino proposta, a metodologia adotada e os resultados obtidos com sua aplicação nos últimos quatro anos. Por fim, na seção 6, encontram-se algumas considerações finais para o trabalho.

\section{Trabalhos relacionados}

No contexto do uso de jogos de apoio ao ensino de programação, Raabe et al. (2015) investigaram a utilização de três jogos de programar, Code Combat, Lightbot e NoBug's Snack Bar, como forma de inserir conceitos de programação para estudantes de Ensino Médio. A pesquisa compreendeu um trabalho de extensão envolvendo quatorze estudantes do Ensino Médio de uma escola pública, que experimentaram os jogos por três semanas. Ao final do experimento, os estudantes fizeram uma avaliação dos jogos, por meio de um questionário com perguntas relacionadas ao perfil dos estudantes e à percepção dos mesmos quanto às facilidades ou dificuldades de se aprender a programar.

Oliveira et al. (2014) apresentaram o jogo GrubiBots Educacional, para o ensino de algoritmos no Ensino Fundamental. O jogo não necessita do desenvolvimento de códigos de programação e pode ser usado para resolver problemas de diversas áreas de conhecimento. Vahldick e Mattos (2008) propuseram um framework em que os alunos programam, em Java, a inteligência de um robô que vive num mundo bidimensional em companhia de outros elementos, como paredes, alienígenas e tesouros. A ferramenta Furbot foi utilizada no primeiro semestre do curso de Ciência 
da Computação e conseguiu aumentar a motivação dos alunos no aprendizado de programação.

Rodrigues et al. (2015) apresentaram um estudo quantitativo voltado à análise do efeito do pensamento computacional no desempenho de estudantes na educação básica. A pesquisa envolveu cento e três estudantes de cursos relacionados à área tecnológica, que tiveram seu desempenho avaliado por meio de suas médias no Exame Nacional do Ensino Médio - ENEM, em relação às suas habilidades em pensamento computacional, mensurado em termos do conhecimento em programação de computadores. O estudo revelou que existe uma correlação moderada entre o desempenho de estudantes ao final da educação básica e as habilidades de pensamento computacional desenvolvidas pela programação. Os resultados também mostraram que estudantes com conhecimentos em programação possuem melhor desempenho em relação aos demais.

Reis et al. (2014) relatam uma experiência de integração entre universidades e escolas, baseada no uso da Robótica Educativa como ferramenta de ensino de lógica de programação, a fim de estimular o raciocínio lógico, o trabalho em equipe e a criatividade dos estudantes da rede pública de ensino. O trabalho aplicou ferramentas da lógica computacional e da manipulação de robôs autônomos móveis, incluindo a linguagem Logo e kits de robótica Legoß. Também foram realizadas algumas competições de robótica regionais. Zanetti e Oliveira (2015) propuseram uma prática pedagógica para ensino de programação por meio de Robótica Pedagógica e Pensamento Computacional, envolvendo seis alunos matriculados em um curso de Ensino Médio integrado ao técnico em Informática. O estudo utilizou a ferramenta de programação visual S4A (Scratch 4 Arduino) e um robô controlado pela plataforma Arduino.

Também merece destaque a plataforma Alice, desenvolvida na universidade Carnegie Mellon (University, n.d.). Alice corresponde a um ambiente de programação 3D que facilita a criação de animações utilizadas para contar uma estória, para jogar um jogo interativo ou para compartilhar um vídeo na web. Trata-se de uma ferramenta de ensino livre projetada para iniciar o estudante no universo da programação orientada a objetos. Morati Jr, Berger, Tavares e Menezes (2012) apresentam o desenvolvimento do jogo Alice no Labirinto das Decisões, implementado por meio do ambiente de desenvolvimento Alice, que coloca o jogador em situações de tomada de decisão que podem ajudá-lo a desenvolver habilidades em situações no mundo real.

Seguindo uma proposta semelhante aos trabalhos relacionados, o presente trabalho discute a utilização do ambiente Robocode para introdução da programação a estudantes do Ensino Médio, mas apresenta como principais diferenciais: o ensino introdutório da programação orientada a objetos em Java por meio de um cenário lúdico de jogos; a criação de meios de se estabelecer uma participação ativa de alunos do ensino superior em parceria com alunos do ensino médio, aproximando os universos e favorecendo o compartilhamento de conhecimentos e experiências; e a utilização de competições para estimular o interesse e a motivação dos estudantes.

Ressalta-se ainda que, até o momento, não faz parte do escopo do projeto a avaliação do desempenho acadêmico dos estudantes em outras áreas em virtude de suas participações no projeto. No entanto, conforme apontado por Rodrigues et al. (2015) em um estudo quantitativo voltado à análise do efeito do pensamento computacional no desempenho de estudantes na educação básica, acredita-se no potencial da abordagem proposta. A pesquisa envolveu cento e três estudantes de cursos relacionados à área tecnológica, que tiveram seu desempenho avaliado por meio de suas médias no Exame Nacional do Ensino Médio - ENEM, em relação às suas habilidades em pensamento computacional, mensurado em termos do conhecimento em programação de computadores. 
O estudo revelou que existe uma correlação moderada entre o desempenho de estudantes ao final da educação básica e as habilidades de pensamento computacional desenvolvidas pela programação. Os resultados também mostraram que estudantes com conhecimentos em programação possuem melhor desempenho em relação aos demais.

\section{Jogos como tecnologias educativas}

No âmbito das teorias de aprendizagem, os jogos assumem papel importante pois permitem a construção de objetos com mais facilidade, como é o caso da linguagem Logo, usada com bastante frequência no Construcionismo de Papert (Lessa Filho, Domínguez, Costa, \& Oliveira, 2015). Em uma visão construcionista, o estudante tem o papel ativo durante o processo de aprendizagem, situação comumente encontrada em um ambiente de jogo educativo, em que o jogador está constantemente aprendendo as regras definidas e formulando estratégias para superar os desafios impostos. Nesse ambiente, também se observa o aspecto interacionista de Vygotsky, que aborda o processo de construção do conhecimento do ponto de vista das interações ocorridas entre o indivíduo e o meio social (Educação, 2013). No universo dos jogos, essas interações ocorrem a todo momento, seja nas relações entre jogadores ou naquelas entre o jogador e o ambiente. Para Vygotsky, a inserção de brincadeiras, jogos e atividades lúdicas nas atividades de ensino desafiam o aluno a atingir o objetivo diante de uma situação-problema, provocando um desenvolvimento que vai além do seu comportamento habitual. O aluno interage com o conhecimento para construir novos conhecimentos, ou seja, aprende enquanto cria. No caso do ambiente Robocode, por exemplo, o estudante aprende com outros jogadores, a partir da observação do comportamento dos robôs adversários para, então, criar novas estratégias para melhorar seus robôs e vencer as batalhas.

Os jogos digitais têm sido vistos como ferramentas pedagógicas poderosas no aumento da motivação do aprendiz, que aprende enquanto vivencia momentos lúdicos e interativos. Diferentes conteúdos educacionais podem ser trabalhados no universo dos jogos, sendo que disciplinas tomadas como difíceis de aprender, como a Física e a Matemática, por exemplo, podem se tornar muito mais interessantes quando o aluno percebe a necessidade de utilizá-las na prática (Santos \& Costa, 2006). No caso do ambiente Robocode, os estudantes trabalham diretamente conhecimentos de Física e Matemática tanto nas movimentações quanto nas ações dos robôs. Assim, acredita-se no potencial do uso do ambiente para melhorar o desempenho acadêmico dos estudantes também em outras áreas. Batista Junior e Santos Filho (2011) propõem o uso de ambientes virtuais como auxiliadores no ensino de Física em escolas públicas do Ensino Médio. R. D. Silva, Viegas e Vieira (2012) abordam o uso de Realidade Aumentada na construção de uma ferramenta lúdica de apoio ao ensino de Física. O sistema foi desenvolvido para utilização no Centro de Ciências da Universidade Federal de Juiz de Fora, que oferece atividades, cursos e programas de formação continuada para professores da educação básica.

Os jogos facilitam a aprendizagem de conteúdos complexos e desenvolvem, no aprendiz jogador, importantes habilidades cognitivas como, por exemplo, a capacidade de resolver problemas, a percepção, a criatividade e o raciocínio lógico (Santos \& Costa, 2006). Como essas habilidades são fundamentais para o aprendizado da programação de computadores, o ensino deste conteúdo 
com o apoio de jogos torna-se promissor.

O ambiente lúdico do jogo constitui uma alternativa pedagógica mais promissora para o ensino de programação frente às técnicas tradicionais de ensino, em especial, por apoiar o aprendiz a vencer as dificuldades que dificultam a construção de um pensamento lógico computacional e consequentemente o aprendizado de lógica de programação. Dentre essas dificuldades, destacam-se: a falta de motivação; dificuldades de estabelecer a relação entre a teoria e a prática; e a dificuldade de assimilar as abstrações e o desenvolvimento de raciocínio lógico-matemático (Cambruzzi \& Souza, 2015).

\section{Plataforma Robocode}

O Robocode (SourceForge, n.d.) foi desenvolvido pela AlphaWorks, divisão pertencente à IBM, com o objetivo de divulgar novas tecnologias de desenvolvimento. Trata-se de um ambiente de simulação de batalha entre robôs, em que se joga programando em Java. O objetivo principal de um jogador é utilizar as classes bases disponibilizadas pelo ambiente na criação do seu próprio robô e colocá-lo em batalha com outros robôs criados por outros desenvolvedores. Para programar um robô, estende-se uma classe da API do Robocode, podendo-se programar robôs guerreiros dos mais variados tipos. Já a partir do primeiro projeto de robô criado, o aluno poderá compreender os principais conceitos de orientação a objetos, tais como classe, herança, métodos e eventos.

Os robôs possuem radares, podem atirar, batem uns nos outros e giram livremente em qualquer ângulo. $\mathrm{O}$ ambiente contém um editor de código-fonte próprio para programar os robôs e um espaço para criar uma arena e configurar a batalha adicionando os robôs. A Figura 1 ilustra uma batalha realizada no Robocode, onde estão representados cinco robôs, chamados: Crazy, Target, Tracker, TrackFire e Fire. Esses robôs são robôs-modelo fornecidos pela plataforma Robocode.

A lógica dos robôs no Robocode está concentrada em métodos, que definem as ações e os movimentos dos robôs. Além disso, a movimentação dos robôs e algumas ações, como atirar em outros robôs, baseiam-se na definição de ângulos pré-especificados, ou seja, requer a aplicação direta de conceitos matemáticos. Como pode ser observado na Figura 2, pode-se alterar: a direção de rotação do robô e do canhão, que podem ser movimentados para a direita ou esquerda, individualmente ou em conjunto; direção de movimentação, podendo ir para frente ou para trás; além das características relacionadas à bala, podendo alterar seu poder de fogo, direção e velocidade (Li, 2002a).

Para as mudanças de direção, seja do robô, do radar, do canhão ou do conjunto, o Robocode adota uma convenção de medidas de ângulo no sentido horário. Como pode ser visto na Figura 3, o ângulo $0^{\circ}$ é a direção "Norte", $90^{\circ}$ é para o "Leste", $180^{\circ}$ aponta para o "Sul" e $270^{\circ}$, para o "Oeste" (Li, 2002b). A velocidade de rotação depende de alguns fatores. Por exemplo, quanto mais rápido o deslocamento do robô, mais lentamente ele consegue girar. Além disso, a velocidade máxima de rotação do radar é maior que a do canhão. Já a localização é dada por um sistema cartesiano de coordenadas, em que o ponto $(0,0)$ está localizado no canto inferior esquerdo do campo de batalha. A unidade de medida de distância é o pixel.

Cada robô é uma entidade que controla o seu próprio ciclo de vida. Quando uma batalha 


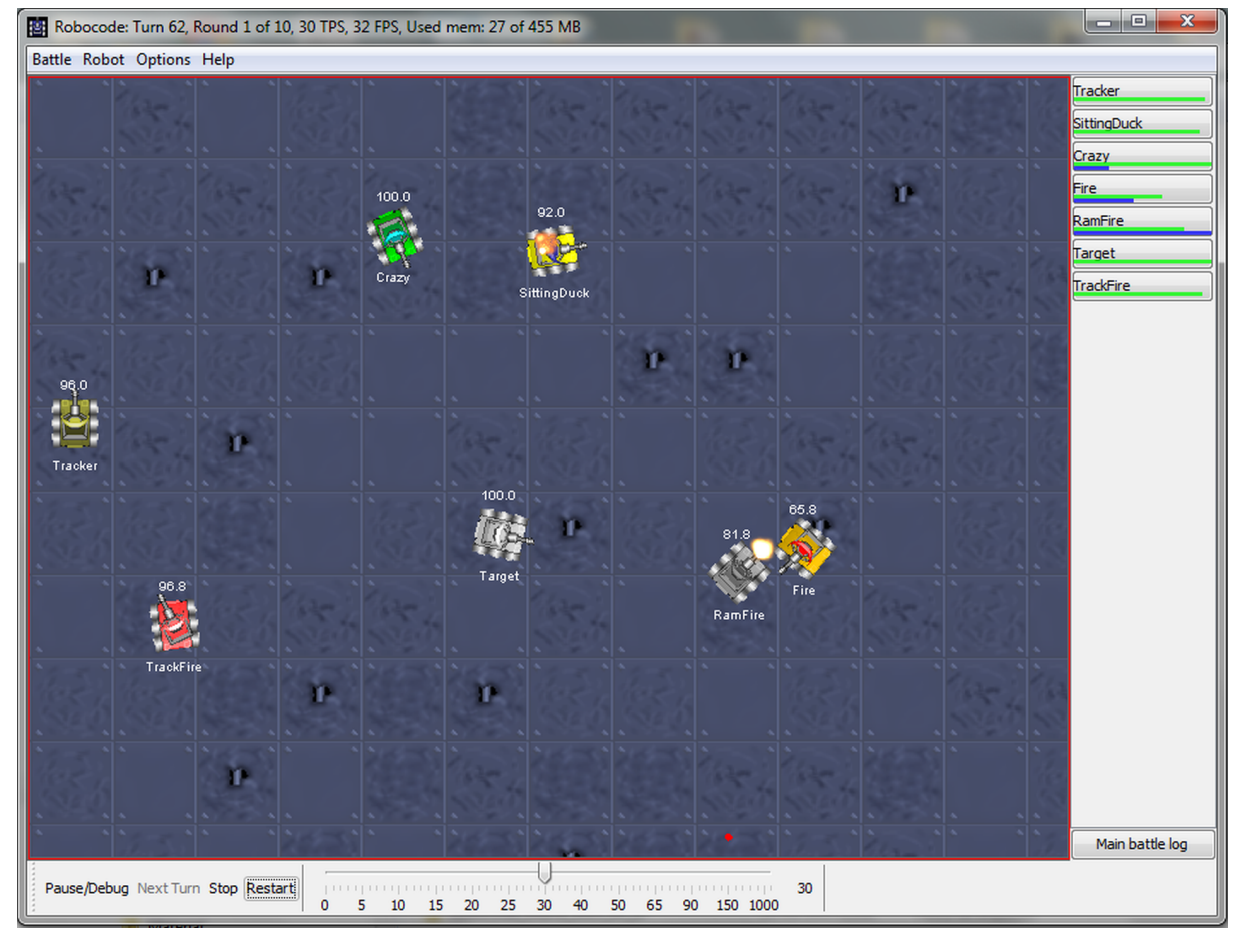

Figura 1: Robocode: Batalha entre robôs.

começa, um método específico é disparado $(\operatorname{run}())$, e, enquanto esse método estiver executando, provavelmente o robô está andando, detectando outros robôs e atirando. A interatividade com o usuário pode ser programada através do tratamento de eventos do mouse e do teclado. Além disso, existem eventos para avisar ao robô quando ele acerta um tiro ou é acertado, quando bate na parede ou em outro robô, quando detecta outro robô, quando ele é eliminado da batalha, ou quando ela é finalizada. Alguns dos eventos básicos que podem ser sobrescritos para melhorar a estratégia do robô são apresentados na Tabela 1.

O trecho de código mostrado no Código 1 pertence ao robô-modelo Fire e mostra a estratégia adotada por este robô quando seu radar detecta outro robô. O objeto $e$, da classe ScannedRobotEvent, recebido como parâmetro pelo método, possui informações sobre o robô detectado, como sua distância e ângulo relativo, permitindo calcular sua localização. Além disso, a classe também

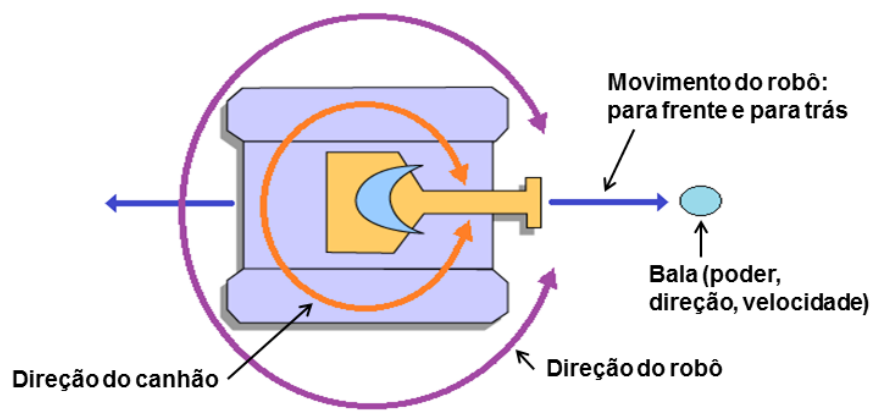

Figura 2: Movimentação do robô. Adaptado de Li (2002a). 


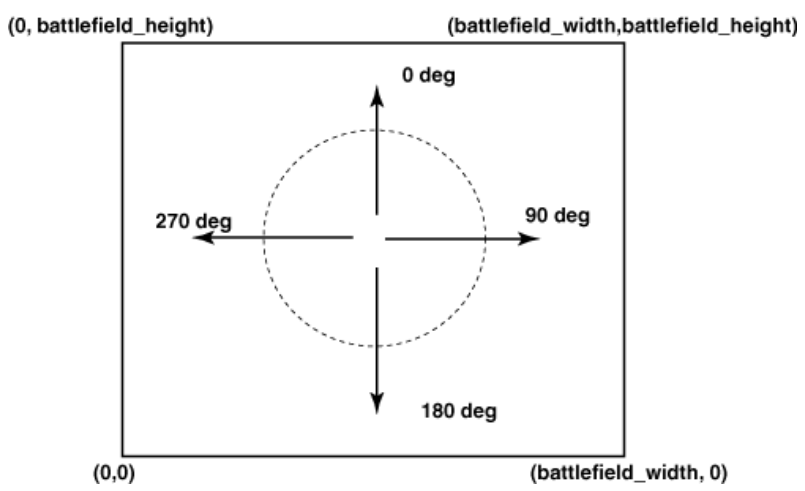

Figura 3: Direções no Robocode (Li, 2002b).

Tabela 1: Eventos durante uma batalha Robocode.

\begin{tabular}{|c|c|}
\hline Evento & Descrição \\
\hline onBulletHit & uma de suas balas atingiu outro robô \\
\hline onBulletHitBullet & uma de suas balas atingiu a bala de outro robô \\
\hline onBulletMissed & uma de suas balas atingiu a parede \\
\hline onDeath & uma de suas balas atingiu a parede \\
\hline onHitByBullet & seu robô foi atingido por uma bala \\
\hline onHitRobot & seu robô colidiu com outro robô \\
\hline onHitWall & seu robô colidiu com a parede \\
\hline onScannedRobot & seu robô detectou outro robô com seu radar \\
\hline onRobotDeath & seu robô morreu \\
\hline onWin & seu robô venceu a batalha \\
\hline
\end{tabular}

possui métodos para retornar a direção em que o robô detectado se move, sua velocidade, seu nome e sua energia restante. Em geral, a ação tomada neste método é a de atirar no inimigo e no Fire isso não é diferente. Porém, neste robô, a intensidade do tiro é alterada conforme a quantidade de energia disponível, já que tiros mais fortes consomem mais energia. O método também considera a distância em que o inimigo se encontra, pois é mais fácil acertar outro robô se este estiver mais próximo, evitando a perda de um tiro forte.

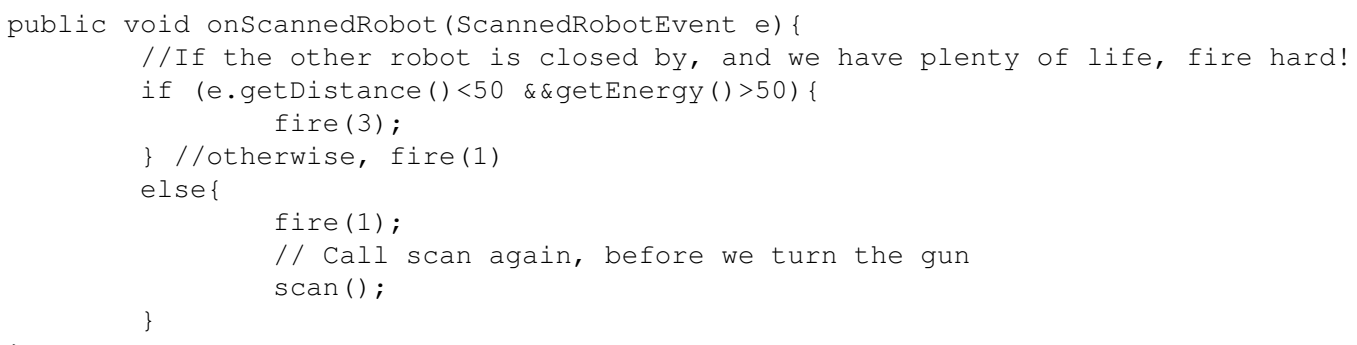

Código 1: Trecho de código da estratégia do robô Fire.

A forma como reage aos eventos também faz parte da inteligência do robô, que pode, por exemplo, optar por ficar sempre próximo à borda do campo de batalha, como o Walls, ou seguir o mesmo robô até que este esteja eliminado, como o Tracker. Um robô pode adotar diferentes 
estratégias conforme a quantidade de inimigos, o tamanho da arena de batalha ou sua quantidade de energia, por exemplo. A plataforma pode ser utilizada para ensinar técnicas avançadas de Inteligência Artificial, que podem ser incorporadas na estratégia do robô.

O'Kelly e Gibson (2006) descrevem o uso de Robocode no ensino de programação utilizando técnicas de PBL (Problem Based Learning). O experimento foi realizado com alunos de graduação em Ciência da Computação, na disciplina introdutória de programação. Segundo os autores, o uso da plataforma Robocode é justificado pela ausência de repositórios de problemas reais na área de Ciência da Computação, no formato apropriado para a aplicação da técnica de PBL. Esse tipo de técnica considera que os aprendizes devem se envolver em tarefas de exploração de ferramentas, descoberta de conhecimento e emprego de criatividade, na busca de soluções para problemas de situações reais de seu meio profissional. O papel do educador é propiciar um ambiente que permita essas atividades, incentivando que os estudantes desenvolvam iniciativa própria, independência e criatividade. A plataforma Robocode forneceu a motivação necessária pois, além do desafio de criar robôs que vencessem seus colegas de classe, os alunos também foram estimulados a participar de competições fora do ambiente escolar. Além dos conceitos de programação, os professores aproveitaram a oportunidade para explorar conceitos éticos como reuso de código e plágio, já que muitas estratégias de robôs estão disponíveis na Internet.

\section{Ensinando programação no Ensino Médio com Robocode}

Esta seção apresenta uma abordagem iterativa para ensino de programação no Ensino Médio, usando a plataforma Robocode. A etapas da abordagem são descritas detalhadamente e os resultados obtidos com a aplicação da mesma nos anos de 2012 a 2015 são relatados.

\subsection{Abordagem de Ensino}

A abordagem de ensino proposta neste trabalho compreende 6 etapas, executadas sequencialmente, a cada iteração anual, conforme ilustra a Figura 4. Essa abordagem representa uma evolução daquela inicialmente proposta por Amaral, Braga e Silva e Pantaleão (2015) e Santana, Guimarães, Santana e Amaral (2013) e será detalhada no decorrer desta seção.

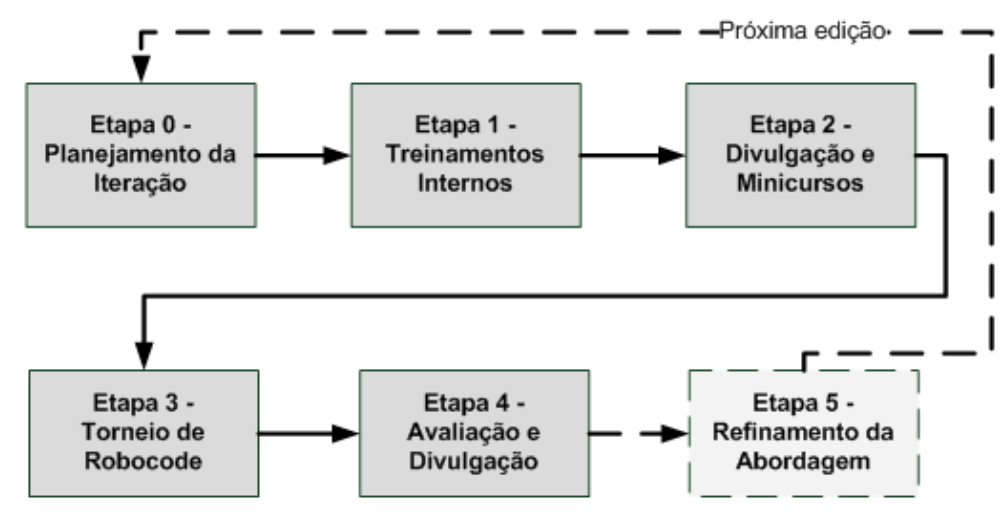

Figura 4: Abordagem Iterativa de ensino de programação com Robocode no Ensino Médio. 
Inicialmente, a Etapa 0 abrange o planejamento da iteração, incluindo a seleção de alunos bolsistas e voluntários, bem como das escolas participantes para levantamento do público-alvo. Nessa etapa, as atividades a serem executadas são planejadas, as tarefas são definidas e alocadas aos membros da equipe e o cronograma é elaborado. O coordenador do projeto realiza uma reunião inicial para explicação da abordagem aos membros da equipe. Uma vez definida a equipe, o coordenador explica as atribuições de cada membro e as relações de trabalho entre eles, conforme ilustra a Figura 4.

Ressalta-se que a participação de alunos bolsistas fica condicionada à obtenção de bolsas institucionais juntos às Pró-Reitorias de Pesquisa e Extensão da UFU, nas modalidades de iniciação científica, iniciação científica júnior e extensão, pleiteadas continuamente junto aos editais institucionais. Para que a abordagem funcione como planejado, vislumbra-se a obtenção de bolsas para alunos de graduação da UFU, que já tenham cursado disciplinas de programação, e para alunos do Ensino Médio, escolhidos dentre as escolas participantes. A equipe é formada também por alunos voluntários, desde que matriculados em um dos cursos superiores da UFU. Outros docentes também podem atuar como membros voluntários da equipe.

Conforme pode ser observado na Figura 5, a relação entre os membros da equipe é guiada pelos papéis de cada um, em um modelo semi-hierárquico, pensado sob o ponto de vista do ensino. Nesse modelo, os docentes transmitem orientações e conhecimentos aos alunos de graduação que, por sua vez, repassam as informações adquiridas aos alunos do Ensino Médio. Esse modelo se perpetua durante todas as etapas da abordagem.

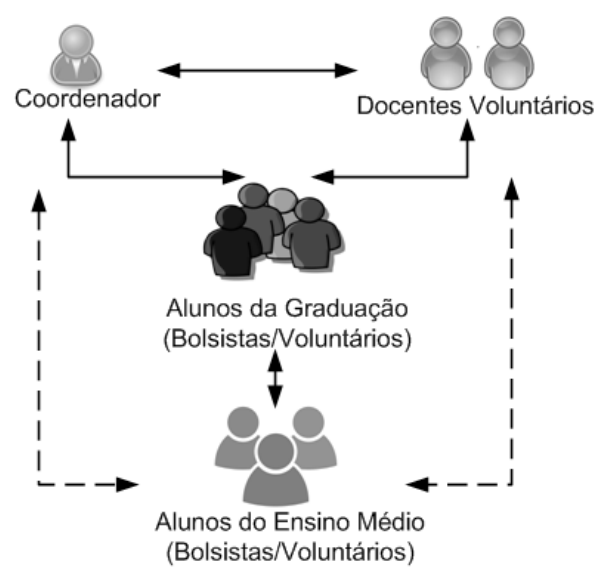

Figura 5: Equipe - papéis e relações.

A Etapa 1 abrange a capacitação interna dos membros da equipe na plataforma Robocode. Para isso, inicialmente, os alunos da graduação, bolsistas e voluntários, que já cursaram disciplinas de programação, incluindo orientação a objetos, recebem um treinamento sobre o Robocode. Esse treinamento é ministrado pelo coordenador do projeto, por um dos docentes voluntários ou ainda por um aluno tutor que já recebeu este treinamento em edições anteriores. Após esse treinamento, os alunos de graduação repassam o conhecimento adquirido aos alunos do Ensino Médio, bolsistas e voluntários. No entanto, para que tais alunos entendam o ambiente Robocode, eles precisam receber um treinamento mais aprofundado em algoritmos e programação. Assim, os alunos de graduação, com o apoio dos docentes, oferecem aos alunos do Ensino Médio, minicursos sobre 
os seguintes tópicos: Introdução à Lógica Matemática e à Lógica de Programação; Algoritmos: Teoria e prática; Linguagem de programação Java; Orientação a Objetos em Java e Ambiente Robocode. Como forma de avaliar preliminarmente o ambiente Robocode, o ensino da linguagem Java e da orientação a objetos é realizado com o auxílio do próprio Robocode, permitindo-se aplicar internamente a estratégia de ensino baseada em jogos educacionais. Como resultado dessa etapa, tem-se a capacitação dos integrantes da equipe para ministrar minicursos ao público-alvo em etapas subsequentes.

Na Etapa 2, ocorrem visitas às escolas de Ensino Médio selecionadas na Etapa 0, para fins de divulgação e levantamento de estudantes interessados em participar do experimento. Sempre que possível, recomenda-se envolver os alunos do Ensino Médio, integrantes da equipe, nas visitas às escolas para que estes façam o convite aos seus pares, pois acredita-se que essa proximidade aumentará a motivação dos estudantes em participar.

Uma vez cumprida a tarefa de visitas às escolas e levantamento do número de estudantes do público-alvo interessados em participar das próximas etapas, realiza-se o minicurso de Robocode. Esse minicurso deve ser ministrado pelos alunos do Ensino Médio, que foram devidamente capacitados na Etapa 1. Os alunos da graduação também participam como tutores, dando suporte aos alunos do Ensino Médio. O número de vagas a ser oferecido dependerá da infraestrutura dos laboratórios de informática onde o minicurso ocorrerá, seja na universidade ou nas escolas envolvidas. Caso nem todas as vagas sejam preenchidas por alunos do Ensino Médio, alunos de graduação da UFU com interesse na iniciativa, podem ser convidados a participar. O minicurso abrange o mesmo conteúdo daquele oferecido aos alunos do Ensino Médio, membros da equipe (Etapa 1), incluindo a utilização do Robocode como ferramenta de ensino.

Após a realização dos minicursos, a Etapa 3 envolve a organização de um evento, voltado à realização de palestras e de uma competição, chamada de Torneio de Robocode. O evento consiste de uma palestra ministrada por convidados, oriundos de outras universidades ou pelos alunos de graduação e da competição em Robocode. A organização do Torneio de Robocode é realizada pelos próprios alunos, com orientação dos docentes envolvidos.

A organização da competição em Robocode compreende as seguintes atividades:

- Definição da dinâmica da competição - orientações gerais, regras, tempo de prova, punições e classificações;

- Busca de locais para realização do evento - auditório para realização da palestra e laboratório de informática para realização da competição em Robocode;

- Busca de patrocínios e recursos - os alunos entram em contato com empresas da região para obtenção de recursos para subsidiar despesas com palestrantes, realização de coffee-breaks, aquisição de premiações para os classificados na competição; e

- Divulgação do evento - os alunos divulgam o evento nos veículos de comunicação da universidade e da região.

Após a realização do Torneio de Robocode, a Etapa 4 compreende a avaliação da iteração e a divulgação dos resultados obtidos. Recomenda-se a utilização de um questionário para se 
obter a avaliação do minicurso sob a perspectiva do público-alvo. Nessa etapa, as respostas do questionário são analisadas e é feita uma autoavaliação por parte dos bolsistas e colaboradores. Em conjunto, todos os membros da equipe levantam pontos positivos e negativos do trabalho realizado e possíveis sugestões para correção das falhas, que são registradas em um documento compartilhado. A seguir, o conhecimento de programação adquirido pelos bolsistas do Ensino Médio é avaliado por meio de tarefas de programação no nível das tarefas propostas ao final da disciplina de programação da graduação, fora do ambiente Robocode.

No que compete aos bolsistas envolvidos, além de receberem treinamentos em algoritmos e na linguagem de programação Java, através do ambiente Robocode, a responsabilidade atribuída a eles, pode lhes proporcionar grande amadurecimento pessoal e profissional. Além de ministrar o minicurso, os alunos têm a oportunidade de participar da organização de um evento, praticando o trabalho em equipe e desenvolvendo seu senso de liderança, experiências que contribuem significativamente para seu desenvolvimento acadêmico e profissional.

Por fim, a última etapa da metodologia abrange o refinamento da abordagem aplicada, segundo a análise dos resultados obtidos na edição atual. Esta etapa conta com sugestões de todos os envolvidos, que após serem cuidadosamente analisadas pelo coordenador, podem ser aplicadas em iterações futuras.

\subsection{Histórico de Aplicação da Abordagem Proposta}

Esta seção relata a experiência com a aplicação da abordagem de ensino proposta entre os anos de 2012 a 2015. Com o intuito de obter os recursos mínimos, necessários e suficientes para viabilizar o experimento, a equipe do projeto buscou apoio financeiro junto à Universidade Federal de Uberlândia - UFU, por meio dos editais de bolsas de iniciação científica júnior (PIBIC-JR), iniciação científica (PIBIC) e de extensão universitária (PEIC), no período de 2012 a 2015.

Os experimentos foram realizados pela UFU, campus Patos de Minas, em conjunto com escolas públicas da cidade de Patos de Minas/MG. Em cada edição, os alunos de graduação selecionados pertenciam aos cursos de Engenharia Eletrônica e de Telecomunicações ou Engenharia de Alimentos e já haviam concluído com êxito disciplinas de programação de computadores. Já os alunos do PIBIC-JR estavam cursando o segundo ano do Ensino Médio. Os recursos financeiros restringiram-se às bolsas concedidas.

A Tabela 2 apresenta a relação de bolsistas e colaboradores participantes das quatro edições de aplicação da abordagem proposta.

Ao longo das quatro edições, cinco escolas estiveram envolvidas com um total de 8 alunos bolsistas, além dos alunos que participaram dos minicursos, assistiram às palestras e também participaram do Torneio de Robocode. As escolas participantes (Tabela 3) pertencem à rede pública do estado de Minas Gerais e estão localizadas na cidade de Patos de Minas.

Como resultados da Etapa 1, ocorreram os treinamentos internos aos membros da equipe. Esses treinamentos foram realizados por alunos de graduação do curso de Engenharia Eletrônica e de Telecomunicações, chamados de tutores. Como os treinamentos foram realizados com o apoio do Robocode, já nessa etapa, foi possível perceber o interesse dos jovens pelo ambiente Robocode, o que torna o processo de aprendizagem mais atrativo aos olhos dos adolescentes. Além disso, 
Tabela 2: Bolsistas e colaboradores por edição.

\begin{tabular}{|c|c|c|c|}
\hline Edição & Bolsista & Quantidade & Órgão \\
\hline 2012 & PIBIC-Jr & 2 & PROPP \\
& PIBIC & 1 & \\
& Colaboradores & 3 & \\
\hline 2013 & PIBIC-Jr & 2 & PROPP \\
& PEIC & 2 & PROEX \\
& Colaboradores & 3 & \\
\hline 2014 & PIBIC-Jr & 2 & PROPP \\
& PEIC & 2 & PROEX \\
& Colaboradores & 4 & \\
\hline 2015 & PIBIC-Jr & 2 & PROPP \\
& PEIC & 2 & PROEX \\
& Colaboradores & 3 & \\
\hline
\end{tabular}

Tabela 3: Escolas participantes por edição.

\begin{tabular}{|c|c|}
\hline Edição & Escola Estadual \\
\hline 2012 & Marcolino de Barros \\
\hline 2013 & Dona Guiomar de Melo \\
\hline 2014 & Prof. Antônio Dias Maciel \\
\hline 2015 & $\begin{array}{c}\text { Doutor Paulo Borges } \\
\text { Deiró Eunápio Borges }\end{array}$ \\
\hline
\end{tabular}

percebeu-se que o raciocínio lógico-matemático é despertado intuitivamente pois o estudante fica motivado pelo desafio de se sair bem no jogo.

Com relação à Etapa 2, que consiste na divulgação e realização do minicurso, a divulgação é realizada junto ao público-alvo, ou seja, alunos de graduação e também do Ensino Médio, pertencentes às escolas participantes. O minicurso teve conteúdo variado durante as edições, sendo que na mais recente optou-se por realizar uma etapa extra, com dicas mais avançadas sobre as estratégias que podem ser usadas nos robôs. A Figura 6 ilustra uma foto dos participantes do minicurso realizado em 2012.

O minicurso de Robocode foi avaliado sob a perspectiva do público-alvo, a partir de um questionário com 8 perguntas, respondido pelos participantes logo após sua realização. Nas primeiras edições, ele foi respondido em papel e suas respostas compiladas posteriormente. Em 2015, foi utilizado um formulário eletrônico. Além disso, optou-se por realizar o minicurso em dias diferentes para os alunos de graduação, que já possuem conhecimentos de programação, e para os alunos do Ensino Médio, para os quais o conteúdo é inteiramente novo.

A fim de mensurar o nível de interesse dos participantes dos minicursos à programação de computadores e avaliar a qualidade das atividades realizadas, um questionário foi aplicado a todos os participantes. A Tabela 4 mostra as perguntas utilizadas, as alternativas disponíveis e as porcentagens de cada resposta, calculadas sobre o total de alunos nas quatro edições do projeto. Como pode ser observado, as atividades realizadas obtiveram uma avaliação positiva pois $100 \%$ dos participantes adquiriram novos conhecimentos e o material utilizado nos minicursos foi adequado, sendo considerado "Muito bom/Bom" por todos os participantes. Os instrutores obtiveram avaliações médias de $94,6 \%$ e $96 \%$ dos participantes classificaram as atividades realizadas como 


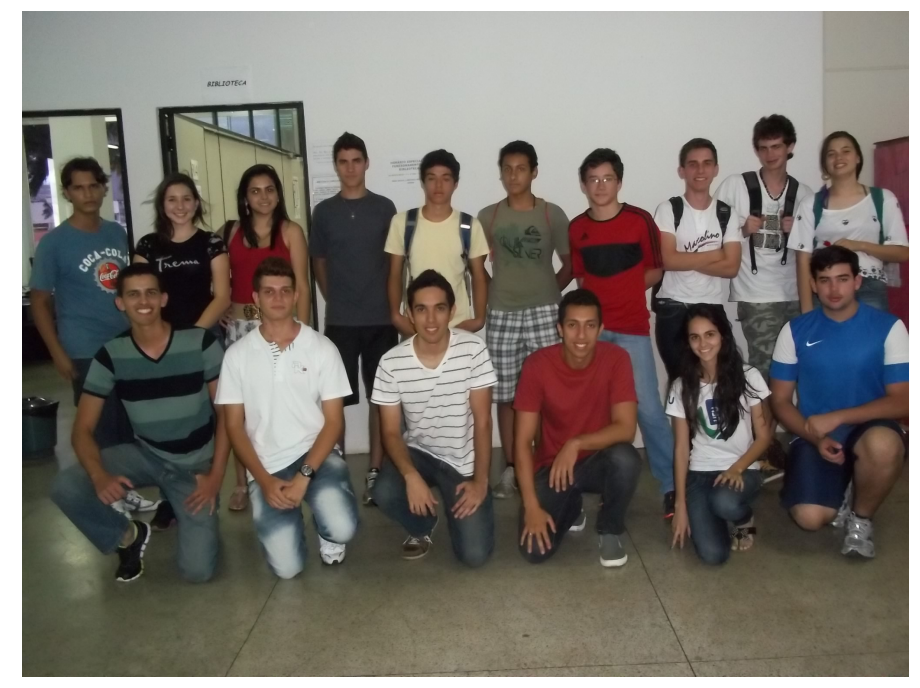

Figura 6: Minicurso de Robocode em 2012.

"Excelente/Muito bom/Bom". A Tabela 4 mostra as perguntas utilizadas, as alternativas disponíveis e as porcentagens de cada resposta, calculadas sobre o total de alunos nas quatro edições do projeto. Em geral, observa-se uma avaliação bastante positiva da metodologia.

Na Etapa 3, ocorre o Torneio de Robocode, que compreende uma palestra e uma competição com Robocode. Os três primeiros colocados são premiados com vários brindes doados pelos patrocinadores, como fones de ouvido, mouses sem fio e pendrives.

Na edição de 2015, os alunos apresentaram o projeto na Feira do Conhecimento do Colégio Tiradentes. Foi uma experiência bastante interessante para eles, alunos do Ensino Médio, participarem de um evento deste tipo. Além disso, na etapa de avaliação (Etapa 4) os alunos foram capazes de desenvolver dois aplicativos simples, um para cálculo de volume de figuras geométricas e outro para solução de equações do segundo grau. Além da lógica para resolução e da sintaxe em Java, os aplicativos foram desenvolvidos com o uso de interface gráfica, e foi possível aplicar na prática o conhecimento sobre eventos obtido no Robocode. Devido aos resultados positivos obtidos, o experimento está sendo realizado novamente em 2016, com término previsto para fevereiro de 2017.

\section{Considerações Finais}

Com o desenvolvimento desse trabalho, percebeu-se, na prática, o quanto o uso de jogos educacionais tem se mostrado uma estratégia de ensino promissora.

Acredita-se que a aprendizagem por meio da investigação venha a desenvolver o senso crítico dos alunos envolvidos, estimulando a busca pelo conhecimento e a competição. Com o Robocode, os alunos do Ensino Médio tiveram a oportunidade de aprender conceitos básicos da programação de computadores, além de desenvolver seu raciocínio lógico-matemático por meio de um ambiente lúdico de ensino, atrativo e interativo. 
Tabela 4: Avaliação do minicurso de Robocode.

\begin{tabular}{|c|c|c|}
\hline Pergunta & Alternativas & Porcentagem \\
\hline P1: Você já conhecia a plataforma Robocode? & Sim & $4 \%$ \\
& Não & $88 \%$ \\
& Vagamente & $8 \%$ \\
\hline P2: O minicurso realizado proporcionou-me novos conhecimentos? & Sim & $100 \%$ \\
& Não & $0 \%$ \\
\hline P3: Os métodos usados no treinamento pelos instrutores foram: & Adequados & $100 \%$ \\
& Pouco Adequados & $0 \%$ \\
\hline P4: O material didático utilizado foi: & Suficiente & $100 \%$ \\
& Insuficiente & $0 \%$ \\
\hline P5: A qualidade (conteúdo) do material didático foi: & Muito Boa & $48 \%$ \\
& Boa & $52 \%$ \\
& Razoável & $0 \%$ \\
& Deficiente & $0 \%$ \\
\hline P6: Avaliação dos instrutores (de 0 a 10): & Média & 9,46 \\
\hline P7: O número de horas diárias do minicurso foi: & Adequado & $91 \%$ \\
& Insuficiente & $7 \%$ \\
& Excessivo & $2 \%$ \\
\hline P8: Classifico, de um modo geral, o minicurso realizado como: & Excelente & $51 \%$ \\
& Muito bom & $41 \%$ \\
& Bom & $4 \%$ \\
& Regular & $2 \%$ \\
& Sofrível & $2 \%$ \\
\hline
\end{tabular}

Acredita-se ainda que a inserção da programação para estudantes do Ensino Médio constitua uma estratégia de captação de alunos para a universidade. Além de favorecer o raciocínio lógico dos estudantes, esse contato prematuro com algoritmos e programação pode prepará-los para cursar disciplinas, direta ou indiretamente relacionadas, em cursos de graduação que eles venham a cursar.

No que diz respeito à motivação dos estudantes, as competições desempenharam bem seu papel. Com a realização dos Torneios de Robocode, foi possível observar o quanto a competitividade influenciou a motivação dos estudantes em aprender e superar desafios. Atividades de pesquisa e extensão como essa mostram-se primordiais na busca pelo fortalecimento da tríade ensino-pesquisa-extensão, em especial, no campus da UFU / Patos de Minas, pela possiblidade de integração entre universidade e sociedade e também pelo potencial de captação de alunos.

Sugestões para trabalhos futuros incluem o uso de técnicas de gamificação como a atribuição de medalhas virtuais durante o aprendizado dos bolsistas (Fire Master, Tracking Wizard, Dodging Warlock) e também o uso da plataforma para o ensino de outras linguagens, como C\# e .NET. Como estudo da eficiência da metodologia, pretende-se avaliar os estudantes do Ensino Médio que já participaram do projeto em termos de suas trajetórias acadêmicas. 


\section{Agradecimentos}

Os autores agradecem à FAPEMIG, CAPES e CNPq pelo apoio financeiro concedido através de bolsas de iniciação científica, relacionadas aos projetos BICJR2012-023, BICJR2012-024, BICJREM2013-087, BICJREM2013-088, BICJREM2014-047, BICJREM 2014-041, IC-JR2015004, IC-JR2015-005, IC-JR2016-028, IC-JR2016-030. Os autores também agradecem às PróReitorias de Pesquisa (PROPP/UFU) e de Extensão (PROEX/UFU) pelo apoio financeiro concedido através dos projetos: Siex 10015/2012, 10946/2013 e 12446/2015.

\section{References}

Amaral, L., Braga e Silva, G., \& Pantaleão, E. (2015). Plataforma robocode como ferramenta lúdica de ensino de programação de computadores - pesquisa e extensão universitária em escolas públicas de minas gerais. Anais do XXVI Simpósio Brasileiro de Informática na Educação, 200-208. doi: 10.5753/cbie.sbie.2015.200

Ap computer science principles. (n.d.). Retrieved from https://advancesinap.collegeboard.org/ stem/computer-science-principles

Astrachan, O., \& Briggs, A. (2012). The cs principles project. ACM Inroads, 3(2), 38-42. doi: $10.1145 / 2189835.2189849$

Batista Junior, E. P., \& Santos Filho, J. V. (2011). Utilizando ambientes virtuais como ferramenta de auxílio no ensino de física em escolas públicas. Anais do XXII SBIE - Simpósio Brasileiro de Informática na Educação, 1086-1089.

Cambruzzi, E., \& Souza, R. M. (2015). Robótica educativa na aprendizagem de lógica de programação: Aplicação e análise. Anais do XXI Workshop de Informática na Escola (WIE 2015), 21-28. doi: 10.5753/cbie.wie.2015.21

Code.org. (n.d.). Anybody can learn. Retrieved from http://code.org/

Educação, P. (2013). Vygotsky e o sócio-interacionismo. Retrieved from http:// www.portaleducacao.com.br/psicologia/artigos/37955/vygotsky-e-o-socio-interacionismo -psicologia-da-educacao

Lessa Filho, C. A., Domínguez, A. H., Costa, F. P., \& Oliveira, P. (2015). Um jogo digital baseado no construcionismo. Revista Brasileira de Informática na Educação, 23(2), 175-189. doi: 10.5753/rbie.2015.23.02.175

Li, S. (2002a). Rock 'em, sock 'em robocode! Retrieved from https://www.ibm.com/ developerworks/java/library/j-robocode/

Li, S. (2002b). Rock'em, sock'em robocode: Round 2. Retrieved from https://www.ibm.com/ developerworks/library/j-robocode2/

Morati Jr, R. G., Berger, A. P., Tavares, O. D., \& Menezes, C. S. (2012). Alice no labirinto das decisões: um jogo para exercitar a tomada de decisão e planejamento. Anais dos Workshops do CBIE - Congresso Brasileiro de Informática na Educação. Retrieved from http://www .br-ie.org/pub/index.php/wcbie/article/view/1926

O’ Kelly, J., \& Gibson, J. P. (2006). Robocode \& problem-based learning. ACM SIGCSE Bulletin, 38(3), 217-221. doi: 10.1145/1140123.1140182

Oliveira, G. A., Bettio, R. W., Rodarte, A. P., Braz, U. E., \& Ferrari, F. B. (2014). Grubi- 
bots educacional: jogo para o ensino de algoritmos na educação básica. Anais do XXV Simpósio Brasileiro de Informática na Educação (SBIE 2014), 584-592. doi: 10.5753/cbie.sbie. 2014.584

PUC-Rio/SERG. (n.d.-a). Polifacets. Retrieved from http://www.serg.inf.puc-rio.br/polifacets

PUC-Rio/SERG. (n.d.-b). Scalable game design brasil (sgd-br). Retrieved from http://www.serg .inf.puc-rio.br/wiki

Raabe, A., Zanchett, G., \& Vahldick, A. (2015). Jogos de programar como uma abordagem para os primeiros contatos dos estudantes com à programação. Anais dos Workshops do IV Congresso Brasileiro de Informática na Educação (CBIE 2015), 1485-1494. doi: 10.5753/cbie.wcbie.2015.1485

Reis, G. L., Souza, L. F., Barroso, M. F., Pereira, E. B., Nepomuceno, E. G., \& Amaral, G. F. (2014). A relevância da integração entre universidades e escolas: um estudo de caso de atividades extensionistas em robótica educacional voltadas para rede pública de ensino. Interfaces, 2(3), 52-76. Retrieved from https://www.ufmg.br/proex/revistainterfaces/index.php/ IREXT/article/view/79

Rodrigues, R. D., Andrade, W., Guerrero, D., \& Sampaio, L. (2015). Análise dos efeitos do pensamento computacional nas habilidades de estudantes no ensino básico: um estudo sob a perspectiva da programação de computadores. Anais do XXVI Simpósio Brasileiro de Informática na Educação (SBIE 2015), 121-130. doi: 10.5753/cbie.sbie.2015.121

Santana, A. L. B., Guimarães, L. G. S., Santana, E. M., \& Amaral, L. R. (2013). Utilização do ambiente robocode como estratégia para ensino de algoritmos e linguagem de programação java para alunos do ensino médio. Anais da III MOCTI - Mostra de Ciência e Tecnologia da cidade de Ituiutaba.

Santos, R. P., \& Costa, H. X. (2006). Análise de metodologias e ambientes de ensino para algoritmos, estruturas de dados e programação aos iniciantes em computação e informática. INFOCOMP Journal of Computer Science, 5(1), 41-50. Retrieved from http://www.dcc .ufla.br/infocomp/index.php/INFOCOMP/article/view/121

Silva, R. D., Viegas, M. A., \& Vieira, M. B. (2012). Ferramenta de apoio ao ensino de física utilizando realidade aumentada. Revista Brasileira de Informática na Educação, 20(3), 60-73. doi: 10.5753/rbie.2012.20.03.60

Silva, T. R., Medeiros, T. J., \& Aranha, E. H. (2014). Jogos digitais para ensino e aprendizagem de programação: uma revisão sistemática da literatura. Anais do XXV Simpósio Brasileiro de Informática na Educação (SBIE 2014), 692-701. doi: 10.5753/cbie.sbie.2014.692

SourceForge. (n.d.). Robocode. Retrieved from http://robocode.sourceforge.net/

University, C. M. (n.d.). Alice. Retrieved from http://www.alice.org/

Vahldick, A., \& Mattos, M. M. (2008). Relato de uma experiência no ensino de algoritmos e programação utilizando um framework lúdico. Anais do XIX SBIE - Simpósio Brasileiro de Informática na Educação. Retrieved from http://www2.uefs.br/roberto/papers/WEI2013 _playful_ecomp_first.pdf

Zanetti, H., \& Oliveira, C. (2015). Práticas de ensino de programação de computadores com robótica pedagógica e aplicação de pensamento computacional. Anais dos Workshops do IV Congresso Brasileiro de Informática na Educação (CBIE 2015), 1236-1245. doi: 10.5753/cbie.wcbie. 2015.1236 